University of Windsor

Scholarship at UWindsor

OSSA Conference Archive

OSSA 9

May 18th, 9:00 AM - May 21st, 5:00 PM

\title{
Fallacy identification in a dialectical approach to teaching critical thinking
}

Mark Battersby

Capilano University

Sharon Bailin

Jan Albert van Laar

Follow this and additional works at: https://scholar.uwindsor.ca/ossaarchive

Part of the Philosophy Commons

Battersby, Mark; Bailin, Sharon; and van Laar, Jan Albert, "Fallacy identification in a dialectical approach to teaching critical thinking" (2011). OSSA Conference Archive. 43.

https://scholar.uwindsor.ca/ossaarchive/OSSA9/papersandcommentaries/43

This Paper is brought to you for free and open access by the Conferences and Conference Proceedings at Scholarship at UWindsor. It has been accepted for inclusion in OSSA Conference Archive by an authorized conference organizer of Scholarship at UWindsor. For more information, please contact scholarship@uwindsor.ca. 


\title{
Fallacy identification in a dialectical approach to teaching critical thinking
}

\section{MARK BATTERSBY}

Department of Philosophy

Capilano University

North Vancouver, BC

Canada V7J $3 H 5$

mbatters@capilanou.ca

\section{SHARON BAILIN}

\author{
Education, \\ Simon Fraser University \\ Burnaby, $B C$ \\ Canada \\ bailin@sfu.ca
}

\begin{abstract}
The dialectical approach to teaching critical thinking is centred on a comparative evaluation of contending arguments, so that generally the strength of an argument for a position can only be assessed in the context of this dialectic. The identification of fallacies, though important, plays only a preliminary role in the evaluation to individual arguments. Our approach to fallacy identification and analysis sees fallacies as argument patterns whose persuasive power is disproportionate to their probative value.
\end{abstract}

KEYWORDS: critical thinking, argumentation, dialectical context, reasoned judgment, comparative evaluation, fallacy identification, probative value, rhetorical effect, dialogue, responding to fallacies

\section{INTRODUCTION: THE DIALECTICAL APPROACH}

The dialectical approach to teaching critical thinking has as its goal enhancing students' ability to make reasoned judgments based on an appropriate inquiry into an issue. We have argued elsewhere for an approach to critical thinking instruction which focuses on a dialectical approach (Bailin \& Battersby 2009; Battersby \& Bailin 2010a; Battersby \& Bailin 20101b) and have instantiated such an approach in our textbook, Reason in the Balance: An Inquiry Approach to Critical Thinking (Bailin \& Battersby 2010). This type of inquiry involves identifying and assessing the relevant pro and con arguments on an issue. Such an assessment of arguments must usually be based on the completion of the inquiry and a comparative evaluation of the arguments. The assessment of the weight or import of even individual arguments cannot usually be done apart from the context in which the arguments are situated. Generally, in order to know how good an argument really is, one has to evaluate it in its dialectical context. Judging how strongly a particular set of premises supports a conclusion frequently requires more information than that supplied in the particular argument. For example, an assessment of the argument that capital punishment deters and that therefore we should bring back capital punishment requires not only a careful examination of the evidence for the deterrence claim, but also a determination of how well the argument from deterrence, even if true, stands up against coun- 
ter arguments to capital punishment such as the problem of the execution of the innocent. Neither of these arguments is fallacious and the complex assessment of their contribution to the question of whether we should have capital punishment requires considering them and other relevant arguments pro and con (see Battersby \& Bailin 2010a, 2010b).

\section{PRIMA FACIE EVALUATION}

Thus the identification of fallacies in individual arguments usually cannot, in itself, constitute an adequate evaluation of the strength of the argumentative support for a claim. Fallacy identification can, however, play a subordinate and preliminary or prima facie role in argument assessment. Although prima facie judgments cannot be definitive about the cogency of an argument, judgments about the fallaciousness of an argument can often be made with considerable confidence. Thus certain arguments can be eliminated from further consideration.

As an example, the argument that we should support capital punishment because there is a long standing tradition of executing murderers can be evaluated and identified as committing a fallacious appeal to popularity or tradition. This provides a basis for not giving consideration and weight to this argument in further considerations of the balancing of pros and cons.

The identification of fallacies also plays a crucial role is ensuring that inquiry dialogues are kept on track and thus contributes to arriving at a reasoned judgment in dialogue situations. Participants in a reasonable dialogue will attempt to avoid making fallacious arguments and should be able to identify and not be distracted or persuaded by fallacious arguments made by others. Nonetheless, coming to a reasoned judgment as a result of a thoughtful exchange of views involves much more than avoiding and identifying fallacious arguments. As with any inquiry, the reasoned judgment must be made by weighing the strength of contending arguments. ${ }^{1}$

\section{ACCOUNTS OF THE NATURE OF A FALLACY}

While our view of fallacies places them in a more subordinate role in argument evaluation than is typical in most approaches to informal logic, we still maintain that the identification and understanding of fallacies plays an important role in inquiry. Our characterization of fallacies departs somewhat from many standard accounts, however.

While traditional accounts associated fallacies with invalidity, informal logicians have moved the analysis away from deduction. In an extensive review of developments with respect to the conceptualization of fallacies, Hansen (2002) offers the following summary:

The survey impresses upon us not only that the ontological component of fallacies as arguments is very firmly entrenched in the tradition (83\%), it also shows that the psychological component, that a fallacy appears to be a better thing of its kind than it really is, is widely supported (61\%). Although the fallacies tradition does not support HHC, it does support a kindred generalization: a fallacy is an argument that appears to be a better argument of its

1 For a discussion of the process of and considerations involved in such a weighing, see Battersby \& Bailin (2010a). 
kind than it really is. No one, however, I believe, has articulated what it is to be a fallacy exactly this way (Hansen 2002: 152).

This idea that fallacies appear to be better arguments than they really are is a central insight about the nature of fallacies, and one which is also elaborated by Walton. In commenting on his own work as well as that of the Pragma-dialecticians, he makes the following observation:

\begin{abstract}
The two most fully developed theories of fallacy so far (Tindale, 1997) are the pragmatic theory (Walton, 1995) and the pragma-dialectical theory (van Eemeren and Grootendorst, 1992). According to the earlier version of their theory, a fallacy is a violation of a rule of a critical discussion where the goal is to resolve a difference of opinion by rational argumentation (van Eemeren and Grootendorst, 1992). [...] According to the pragmatic theory (Walton 1995, 237-238), a fallacy is a failure, lapse, or error that occurs in an instance of an underlying, systematic kind of wrongly applied argumentation scheme or is a departure from acceptable procedures in a dialogue, and is a serious violation, as opposed to an incidental blunder, error, or weakness of execution. [...] The problem is that neither theory has fully taken into account that longstanding intuition, very much evident in Aristotle's treatment of the sophistici elenchi, that fallacies are deceptive. They are not just arguments that prejudice efforts to resolve a difference of opinion, wrongly applied argumentation schemes, or departures from acceptable procedures in a dialogue, although they are all that. They are arguments that work as deceptive stratagems. They are arguments that seem correct but are not (Walton 2010: 279).
\end{abstract}

In an attempt to address why it is that fallacies seem correct but are not, Walton suggests that the concept of heuristic may provide an explanation. He notes that the heuristics involved are inferential tendencies which by and large serve us well, but which also can on occasion lead to unwarranted inferences. The work of Amos Tversky and Kahneman (cited above) has demonstrated how these heuristics can lead to unwarranted inferences, while the work of Gigerenzer (1999) and others has shown how these "simple and frugal" heuristics can often lead to reasonable, if tentative conclusions (Walton 2010).

According to Walton's new analysis, the fallacy results from using a heuristic which is often appropriate but is not a reliable guide for the case in question. In our view, fallacies are indeed arguments which seem correct but are not. Our characterization of fallacy attempts to capture and build on this insight. We further agree with Walton that heuristics could indeed be one of the sources of fallacious reasoning. We would argue, however, that they are by no means the only source.

\title{
4. OUR ANALYSIS OF FALLACIES
}

We define a fallacy as an argument pattern whose persuasive (rhetorical) power greatly exceeds its probative value (i.e., evidential worth).

Probative value, as it is used in law, is the legal weight or evidential worth that a piece of evidence should be given when making a judicial finding. Evidence of high probative value includes items such as DNA and finger prints; items of low probative value are items such as hearsay or observations done under poor lighting conditions. Importantly, courts sometimes refuse to hear evidence even though it has probative value. ${ }^{2}$ The

\footnotetext{
${ }^{2}$ In R. v. B., Justice Maclachlin wrote:

"The analysis of whether the evidence in question is admissible must begin with the recognition of the general exclusionary rule against evidence going merely to disposition.... (E)vidence which is adduced
} 
refusal to hear this evidence is based on the court's belief that the evidence is too "prejudicial" i.e., the evidence's persuasive power greatly exceeds its probative value. A good example of this is the prohibition on similar fact evidence. Similar fact evidence is evidence that the accused has committed previous crimes that were similar to one that he is currently charged with. In our text we illustrate the court's concern with the following example:

... let's imagine that "Bill" is accused of using a ladder to get to the second story balcony of an apartment and then entering through the unlocked door and stealing a television set. Being caught with the stolen television set would have strong probative value for his guilt (of course he might have been given it, so it is not conclusive evidence). On the other hand, if it turns out that Bill has been convicted of breaking into the second floor of apartments before, you might think that this too is relevant evidence.

But such similar fact evidence is usually not allowed to be presented to the court, not because it has low probative value, but because it is too persuasive. A jury (perhaps even a judge) on hearing that the accused has been convicted of a similar crime will be strongly inclined to find this evidence very persuasive. Too persuasive. But from a probative point of view, this evidence is very weak because Bill's particular method of crime is very common and could have easily been used by someone else. The crime he is accused of is not only similar to his past crimes, but similar to crimes committed by many others, meaning that the similar fact pattern has low probative value. But because this evidence carries so much more persuasive power than probative value, the courts generally prohibit the presentation of such evidence (Bailin \& Battersby 2010:63).

We can illustrate how our concept of fallacy works by applying our analysis to an example from one of the dialogues in our text:

McGregor: Your friend Lester is typical of people on the minimum wage. He lives at home with his parents. I don't see why he needs a lot of money, except for frivolities like beer and movies. So raising the minimum wage will just be helping a bunch of well off kids have more spending money. Hardly a good way to help the poor (Bailin \& Battersby 2010: 62).

The tendency, illustrated by McGregor, of confidently asserting a generalization based on one example is the common fallacy of anecdotal evidence. Note that McGregor's example is not irrelevant to the generalization about minimum wage workers -- after all, this is a case supporting his generalization. Individual experiences are often relevant to supporting a generalization and can play a key role in refuting generalization. Thus such appeals to personal experience usually have some probative value. The problem is that humans have a tendency to assume that their experiences are typical and therefore an adequate basis for generalizing. ${ }^{3}$ The fallacy results from taking very limited evidence that is subjectively powerful and persuasive and crediting it as if it strongly supports a generalization.

solely to show that the accused is the sort of person likely to have committed an offence is, as a rule, inadmissible. Whether the evidence in question constitutes an exception to this general rule depends on whether the probative value of the proposed evidence outweighs its prejudicial effect."

In Sweitzer, Justice McIntyre of Canada Supreme Court wrote:

"... where similar fact evidence is tendered ... its admissibility will depend upon the probative effect of the evidence balanced against the prejudice caused to the accused by its admission whatever the purpose of its admission." http://www.duhaime.org/LegalDictionary/S/SimilarFactEvidence.aspx

3 Extensive research by Tversky, Kahneman and others on the assumption of representativeness supports this observation. People expect their experience to be representative just as they expect a sequence of dice roles to look like a random distribution. See Tversky \& Kahneman (1974). 
To return to Walton's analysis, this instance could be seen as a misapplication of the representativeness heuristic described by Tverksky and Kahneman, exactly fitting the pattern identified by Walton. We would argue, however, that "natural" heuristics are just one source of persuasiveness that can lead to crediting arguments grossly in excess of the probative value of the reasons presented. In this case, the power of anecdotal evidence also comes from the compelling power of narrative. Both these rhetorical factors contribute to the tendency to give undo weight to what is after all a very small and biased sample. Fallacies are not just created by the misapplication of heuristics, but also by any factor which causes the argument to be significantly more persuasive than warranted by its probative value. As Walton noted in an earlier paper, emotional appeals are also an aspect of many fallacies: "Emotional appeals are not necessarily fallacious arguments, but when they do become categorized as fallacies, it is because they are weak and irrelevant moves in argument" (Walton 1987: 330).

What he fails to note is that in a fallacious argument, the emotional appeal (which we take to be an example of the argument's non rational but persuasive appeal) tends to exceed whatever probative value is present in the argument. In the article on the ad hominem from which this quotation is taken, he notes that many cases of circumstantial ad hominem remarks about the author are relevant, especially when they provide a basis for raising doubts about the reliability of the claims of the author:

This type of ad hominem argument can be reasonable in some cases because inconsistency of an arguer's position should reasonably be open to criticism or questioning. However, it can become fallacious if the arguer's statement is rejected too strongly, or if the issue is evaded (Walton 1987: 327).

Why then is it a fallacy? Because what is usually inferred from the attacks on the proponent's motivation and circumstances is that the position and arguments of the proponent can simply be dismissed. The effect of persuading the listener to dismiss the argument is the rhetorical effect. The ad hominem tends to produce a confident dismissal of an argument which is not warranted despite whatever probative value can be given to the circumstantial considerations regarding the author.

\section{APPLYING THE ANALYSIS TO FORMAL FALLACIES}

This same analysis of a fallacy as an argument whose persuasive power greatly exceeds its probative value can also be applied to formal fallacies, e.g., affirming the consequent, as can be demonstrated by the following simple example:

(1) If the car runs, then it has fuel

(2) The car has fuel

(3) Therefore it will run

This argument also exhibits the characteristic of having some probative value -- in this case the second premise does provide some support for the conclusion. But when pre-

4 In a recent exchange on Argthry we were invited to share our impressions of the status of critical thinking in post secondary education. Few could resist the temptation of sharing anecdotes, with the suggestion, either explicit or implicit, that these stories and impressions constituted reasonable evidence for a generalization. 
sented as a deductive argument with the truth of the premises supposedly guaranteeing the truth of the conclusion, it is fallacious. The fact that the car does have fuel has probative value for the claim that it will run, but offered as a deductive argument, its rhetorical effect is to give an unwarranted air of certainty where it should only convey probability.

\section{PEDAGOGY}

Given our analysis of fallacies, we describe each fallacy in our text as having two aspects: 1. "logical error" - an explanation of why the argument has limited or no probative value, and 2. "rhetorical effect" - an explanation of why the argument has a tendency to be persuasive. The most common effect of a fallacious argument is to induce a level of conviction unwarranted by the probative value of the argument. Sometimes the rhetorical effect is also destructive of an effective dialogue, producing not only unjustified conviction, but derailing the whole dialogue from its purpose. Thus, even if the claim (e.g., that someone is motivated by sexism) is likely, the effect on the dialogue is to switch it to a discussion of the participant's motives and away from the issue in question. We insist on the identification of both aspects of a fallacy because failure to understand the rhetorical aspect of the fallacy makes a person less able to resist its siren call and more likely to miss the reasoning error that is the basis of the fallacy.

Note that we are not claiming that all of these rhetorical aspects are necessarily intentional or even intentionally misleading. That is why we describe these fallacious rhetorical moves as rhetorical effects not strategies. Fallacious arguments can, and perhaps often are, made intentionally. But we have all slid into fallacious reasoning unintentionally. Who has not over generalized from a single experience?

To see how this analysis works, we excerpt from our text our description of the ad hominem.

\section{AD HOMINEM:}

Arguers commit the fallacy of ad hominem if they reject a proponent's argument on the basis of critical remarks about the proponent rather than the proponent's argument To be clear, not any personal attack is guilty of the ad hominem fallacy. The fallacy is committed only when the remarks about the proponents are used as grounds to inappropriately dismiss their argument.

Rhetorical Effect: Discredits an argument by attacking the author's background and behaviour and shifts the argument to the author and away from the issues at hand. In a dialogue, such a move often leads to the author defending their personal behaviour or background instead of staying focused on the issue at hand. The use of the ad hominem is especially detrimental to conducting a dialogue because it not only distracts from the issue at hand, but it also tends to inflame people's emotions.

Logical Error: If the author has presented credible evidence and arguments, the proponent's background or behaviour is largely irrelevant to the logical worth of the argument. When arguments are presented, the issue must be decided on the merits of the argument, not on the qualities of the author.

The situation is different if the proponent is claiming that we should accept their argument because of some fact about them, such as being an expert in the field. In such cases, evaluating the source of the argument can be relevant. What makes ad hominem remarks fallacious is not that facts about the author are always irrelevant, but rather that we usually tend to give such claims too much weight when assessing an argument- they have more persuasive impact than probative value. (Bailin \& Battersby 2010: 65) 
We also note that some considerations about the author's circumstances can be legitimate, illustrating our general point that what makes ad hominem arguments fallacious is the excessive degree to which people find remarks about an author a basis for dismissing their argument. But information about the author is sometimes relevant because it can form part of the basis on which we decide to trust the author's claims or believe that crucial counter arguments have not been ignored. As Walton notes above, one can and should use knowledge of a person's likely biases to inform the process of evaluation of their arguments (Walton 1987).

\section{RESPONDING TO FALLACIES}

Another role of fallacy identification in a dialectical approach to critical thinking is its role in guiding an effective response. For fallacy identification to be a useful tool in reasoning and dialogue participation, a student also needs to be able to use this identification to respond effectively. While this understanding is useful in writing responses to arguments, it is especially crucial to have an effective means of responding to fallacies in a dialogue. Teaching students to identify fallacies and their rhetorical effect provides them with the means for preventing fallacious arguments (intentional or not) which may lead the discussion off the rails.

The key to responding to fallacies effectively is 1) to notice the rhetorical effect and resist its temptation, 2) to recognize the logical error, and 3) to address the logical error in a manner that supports the continuation of a respectful exchange of views. In the case of many fallacies, the key is not to be distracted by arguments of limited or no relevance and to keep the discussion on topic. Effective responses identify the fallacy without name calling and keep the discussion focused on the issue in question.

Below are suggestions from our text on how to respond to the ad hominem. Notoriously people respond to personal attacks in an argument by defending themselves against the attack ("I am not a hypocrite. While only yesterday...") instead of returning to the issue in question. This is why it is important to identify the rhetorical impact of a fallacy ("I am being attacked, which will distract me from the issue"). The responses below illustrate a variety of ways of responding that keep the discussion on track:

- $\quad$ Yes, he may seem to you to be crazy (neurotic, upset), but still he has a point. The arguments he made seem pretty good to me.

- Even if she does work for the ..., is friends of..., is married to..., you still have to listen to her point. I mean she made a pretty good argument about...

- This isn't about me. The issue is ... $\quad$ (Bailin \& Battersby 2010: 206)

\section{CONCLUSION}

While fallacy identification plays primarily a preliminary and subordinate role in our view of critical thinking as inquiry, we still provide students with a somewhat novel and, we believe, powerful method for identifying and analyzing fallacies. Moreover, while not relating fallacy identification directly to the violation of dialogic rules, we do emphasize the need to identify, avoid. and respond effectively to fallacies that occur during a dialogue. 


\section{MARK BATTERSBY AND SHARON BALIN}

\section{REFERENCES}

Bailin, S., and Battersby, M. (2010). Reason in the Balance: An Inquiry Approach to Critical Thinking. Whitby, Ont.: McGraw-Hill.

Bailin, S., and Battersby, M. (2009). Inquiry: A dialectical approach to teaching critical thinking. In: Ritola, J. (ed.). Argument Cultures, Proceedings of OSSA 8. CD-ROM. Windsor, ON: OSSA.

Battersby, M., and Bailin, S. (2010a). Guidelines for reaching a reasoned judgment. Symposium on Conductive Reasoning, University of Windsor.

Eemeren, F.H. van, and Grootendorst, R. (1992). Argumentation, Communication and Fallacies. Hillsdale, N. J.: Erlbaum.

Eemeren, F.H. van, Garssen, B., and Meuffels, B. (2009). Fallacies and Judgments of Reasonableness. Dordrecht: Springer.

Gigerenzer, G., Todd, P. M., and the ABC Research Group (1999). Simple Heuristics That Make Us Smart. Oxford: Oxford University Press.

Hansen, H.V. (2002). The straw thing of fallacy theory: The standard definition of fallacy. Argumentation $16,133-155$.

Tindale, C. W. (1997). Fallacies, blunders and dialogue shifts: Walton's contributions to the fallacy debate. Argumentation 11, 341-354.

Tversky, A., and Kahneman, D. (1974). Judgment under uncertainty. Science 185, 1124-1131.

Walton, D. (1995). A Pragmatic Theory of Fallacy. Tuscaloosa: University of Alabama Press.

Walton, D. (2010). Why fallacies appear to be better arguments than they are. Informal Logic 30(2) 159-184.

Walton, D., and Gordon, T.F., (2009). Jumping to a conclusion: Fallacies and standards of proof. Informal Logic 29, 215-243.

Walton, D. (1992). Which of the fallacies are fallacies of relevance? Argumentation 6, 237-250.

Walton, D. (1987). The ad hominem argument as an informal fallacy. Argumentation 1, 317-331. 


\title{
Commentary on "FALLACY IDENTIFICATION IN A DIALECTICAL APPROACH TO TEACHING CRITICAL THINKING" by Mark Battersby and Sharon Bailin.
}

\section{JAN ALBERT VAN LAAR}

\author{
Faculty of Philosophy \\ University of Groningen \\ Oude Boteringestraat 52 \\ The Netherlands \\ j.a.van.laar@rug.nl
}

\section{INTRODUCTION}

In the dialectical approach of Mark Battersby and Sharon Bailin, teaching critical thinking has as its goal "enhancing students' ability to make reasoned judgments based on an appropriate inquiry into an issue." In their paper, they focus on the role of fallacy identification in enhancing this ability. The central idea is that fallacy identification is an important part of the evaluation of arguments, but that it does not exhaust it. I agree with their view, and try to add to their case by way of three critical comments. First, I shall try to make it plausible that, contrary to the authors' view, fallacy analysis does not play a merely preliminary or subordinate role in the evaluation of an argumentative text or speech. Second, I shall elaborate on my position that fallacy analysis does not always suffice when evaluating argumentation, not because fallacy analysis would be insufficiently sensitive to the dialectical context, but rather because there are argumentative norms, the violation of which do not constitute fallacies, but rather argumentative weaknesses or institutional faults. Third, I shall contend that fallacy identification should be supplemented with the dialectical testing of the alleged identifications of fallacies.

\section{THE ALLEGEDLY PRELIMINARY ROLE OF FALLACY ANALYSIS}

The authors point out that fallacy identification can play a "subordinate and preliminary or prima facie role in argument assessment" but that it does not suffice for arriving at an adequate evaluation, which is required for a reasoned judgment, for the reason that "the reasoned judgment must be made by weighing the strength of contending arguments." The authors' argument suggests that they use a notion of fallacy, according to which it is possible to identify all the fallacies in a text or speech, without having taken the complete dialectical context into account. ${ }^{1}$

However, it is plausible that fallacies can be committed in the final stage of a discussion, in which the merits of both contending sides are weighed in an attempt to find

1 Battersby and Bailin define "fallacy" as "an argument pattern whose persuasive (rhetorical) power greatly exceeds its probative value (i.e., evidential worth)." An undesirable consequence of this definition seems to be that an argument must be judged fallacious in case it has a low probative value and a great persuasive power ("for the intended audience," I would add), even if the protagonist of this argument is completely honest about the low probative value of the argument and does not in any way exploit the disposition in the addressed audience to overestimate the argument's probative value.

Zenker, F. (ed.). Argumentation: Cognition and Community. Proceedings of the $9^{\text {th }}$ International Conference of the Ontario Society for the Study of Argumentation (OSSA), May 18-21, 2011. Windsor, ON (CD ROM), pp. 1-4. 
out whether or not the standpoint at hand has been successfully defended. Part of the pragma-dialectical model of an ideally critical discussion, for example, is a concluding stage in which the parties attempt to find out whether the initial differences of opinion have been resolved, and if so, in whose favor. This stage is governed by a rule that states, among other things, that a protagonist is not allowed to maintain his standpoint if the antagonist has conclusively attacked the standpoint. ${ }^{2}$ Thus, in order to put forward a sustainable judgment to the effect that a protagonist is recalcitrant in this specific manner, the evaluator must make a survey of all the critical responses put forward by the antagonist, as well as of the ways in which the protagonist has responded to them. This implies that the contending arguments of the antagonist addressed must also have been taken into account. Of course, the evaluator may dismiss an argument, or a different kind of contribution to the dialogue, as a fallacy as a preliminary verdict, before having considered the full dialectical context, but when doing so, she merely anticipates on what she expects to be her final assessment. A similar analysis applies to the fallacy of failing to retract one's critical doubt after having been provided with a conclusive defense of a standpoint. ${ }^{3}$ To conclude, at least some fallacy judgments require an extensive knowledge of the contending arguments, and therefore the assumption of Battersby and Bailin, to the effect that an evaluator may first identify the fallacies within individual arguments, and then proceed to determine the strength of the contending arguments, cannot be upheld unconditionally. ${ }^{4}$

Fallacy identification can play a prima facie role in argument evaluation. Nevertheless, they also must play an important role in the final stages of argument evaluation, when the merits of each of the positions in the discussion are added up and weighed against each other. This suggests that the analysis of fallacies is important in preliminary as well as in more advanced stages of inquiry dialogues that aim at reasoned judgments.

\section{BEYOND FALLACY ANALYSIS}

I agree with the authors that the dialectical context must be closely examined when evaluating an argument. As we have seen, one reason is that a sustainable judgment to the effect that a move is fallacious sometimes requires extensive knowledge of the dialectical context. Another reason is that a full-fledged evaluation goes beyond an analysis of the fallacies.

The evaluation of an argument is the activity in which it is determined whether, and if so, to what extent, an argument conforms to a chosen set of standards, or norms, or rules, or to an ideal or desired state. I assume that argument evaluation is best carried out in the light of a specification of an argumentative ideal by way or three kinds of norms (Krabbe and van Laar 2011). First, there are rules for critical discussion, which distinguish between speech acts (among which arguments) that are legitimate, in the sense of being instrumental to the resolution of disputes, and those that are not legitimate. The latter speech acts are defined as fallacies (van Eemeren and Grootendorst 2004). For example,

2 This is stated in Rule 14 (van Eemeren and Grootendorst 2004: 154). The meaning of "conclusive attack" is defined in Rule 9 (p. 151).

3 This is, in the pragma-dialectical view, also a violation of Rule 14 (van Eemeren and Grootendorst 2004: 154).

4 I am sympathetic to the attempt to account for the persuasive nature of fallacies. Note that a different way of accounting for the persuasive aspects of many fallacies is provided by the theory of strategic maneuvering (van Eemeren and Houtlosser 2002). 
according to the pragma-dialectical commandments for critical discussion, it is not allowed to falsely present a proposition as a common starting point. Thus, falsely presenting a premise as a common starting constitutes a type a fallacy (Van Eemeren and Grootendorst 1992: :151-154). Second, there are norms of optimality, which distinguish between speech acts that are of better quality from those that are of poorer quality. The latter are weak moves, and possibly even blunders. For example, even if a premise of an argument has not been falsely presented as a common starting point, it can still fail to be a common starting point, and thereby constitute a weak (but non-fallacious) part of the argument. Third, there are institutional norms, which distinguish between moves that are appropriate within a particular type of (more or less institutionalized) context from those that are inappropriate. For example, even though it can be a common starting point that the defendant has stated that he is guilty, the premise that expresses this common knowledge can still be inappropriate for the reason that this evidence is legally inadmissible, for example by being obtained from an illegally taped conversation. These errors can be labeled (institutional) faults.

Another example of a fault seems to be provided by Battersby and Bailin in the legal example of the evidence that, in the judge's eye, is too persuasive for the jury, and that might therefore hinder the jury in arriving at a reasoned judgment. The judge seems to be afraid that the jury will make an argumentative mistake by conceiving of the argument at hand as decisive, thereby assigning insufficient weight to other relevant considerations. In other words, the judge wants to avoid the jury to commit the fallacy of jumping to a conclusion. Apparently, there is an institutional rule that the judge can appeal to when dismissing such evidence as "prejudicial."

To conclude, the evaluation of an argument extends beyond fallacy analysis, and includes judgments of argumentative weakness and of institutional fault.

\section{THE DIALECTICAL NATURE OF FALLACIES}

The dialectical approach of the authors can be extended, along lines indicated by Hamblin (1970: Chapter 9), by accepting a consequence of conceiving of "fallacy" as an evaluative term, rather than as a descriptive one.

The expression "fallacy identification" suggests that fallacy analysis may result in a neutral list of the errors that have been committed within a text or speech. Brian Yoder makes fun of this assumption when referring to his online catalogue of fallacies, by writing: "Brian doesn't like illogical arguments, so he has collected some dangerous fallacies and put them behind bars where you can safely view them in his Fallacy Zoo."5

In contradistinction to such a perspective, Hamblin proposes in his last chapter of the book "Fallacies" to view "[fallacy of] equivocation" not as a description of a particular erroneous argumentative species, but as a point of order, by which someone can be charged of having committed a particular kind of argumentative mistake. To "identify a fallacy" in an argument is, in this view, a way to criticize that argument in a particular manner. To state that an argument constitutes a particular fallacy, is to make a charge against that argument. An argument is, or is not, a fallacy-according-to-someone. According to such a full-fledged dialectical perspective on fallacies, fallacy charges themselves are dialogical contributions and can be evaluated as such. Given the threefold distinction

5 http://home.earthlink.net/ byoder/ 
discussed earlier, a fallacy charge could be wrong in the sense of being an institutional fault, or an argumentatively weak move, or, indeed, a fallacious move itself.

Battersby and Bailin are on this track when they explain how to respond to fallacies. The requirements they formulate on fallacy charges are plausible ones: make it clear what is wrong with the fallacy, but refrain from name calling and keep focused on the issue at hand, in order to invite the other side to proceed with the discussion.

Hamblin's view suggests that skills in argument evaluation are, in addition, furthered by inviting students to critically assess the fallacy charges. By critically assessing fallacy charges, students are forced to get a clear view of the characteristics of the various types of fallacy, and of the clauses of the accompanying definitions. Thus, the dialogues of the authors, which end in an adequate response to an alleged fallacy, should be extended with a move in which fallacy charge is challenged and critically tested.

B: Vote for my party!

A: You are a hypocrite. (Plausibly, a kind of ad hominem fallacy.) ${ }^{6}$

B: This isn't about me. This is about the policies advocated by my party. (An admissible critical response to the alleged fallacy; More in particular, a fallacy charge.)

A: Since I must vote for a person, I am entitled to require him to be trustworthy. (An admissible critical response to the fallacy charge.)

By teaching fallacies in such a dialectical manner, one conveys the message that fallacy judgments can be expected to be themselves matters of contention. A central task of argumentation theory should be to develop the means with which discussants can debate themselves what the merits are of their arguments and of the moves with which they evaluate their arguments.

\section{CONCLUSION}

First, fallacy analysis may play a role both in early and in more advanced stages of argument evaluation. Second, a complete evaluation of an argumentative text or speech also includes the identification of argumentative weaknesses and of institutional faults. Third, teaching fallacy analysis can be done in a dialectical fashion by examining both how to raise constructive fallacy charges and how to challenge such fallacy charges.

\section{REFERENCES}

Eemeren, F.H. van, and Grootendorst, R. (1992). Argumentation, Communication, and Fallacies: A Pragma-Dialectical Perspective. Hillsdale, NJ: Erlbaum.

Eemeren, F.H. van, and Grootendorst, R. (2004). A Systematic Theory of Argumentation. Cambridge: Cambridge University Press.

Eemeren, F.H. van, and Houtlosser, P. (2002). Strategic manoeuvring in argumentative discourse: A delicate balance. In: Eemeren, F.H. van, and Houtlosser, P. (eds.), Dialectic and Rhetoric: The Warp and Woof of Argumentation Analysis (pp. 131-159). Dordrecht: Kluwer Academic.

Hamblin, C.L. (1970). Fallacies. London: Methuen.

Krabbe, E.C.W., and Laar, J.A. van (2011). The Ways of Criticism. Argumentation 25, 199-227.

6 According to Battersby and Bailin, in order for an ad hominem fallacy to be a fallacy, it must instantiate a particular argument pattern. Unfortunately, it has not been made clear by the authors what argument pattern an ad hominem fallacy such as this one exhibits. 